ALL MATERIAL FOR THE CASE IS 0.250" UNLESS OTHERWISE SPECIFIED. ALL CASE MATERIAL IS ANODIZED BLACK

ALL GROOVED FITS 0.050" DEEP

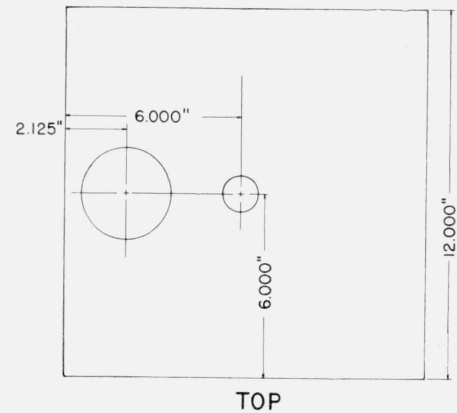

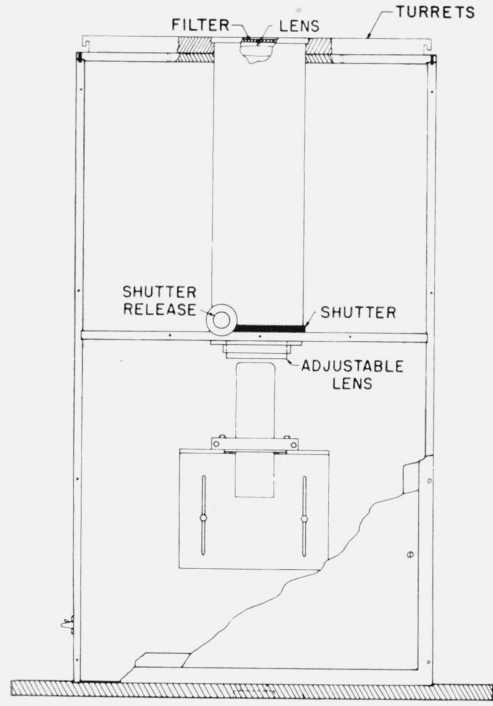

LEFT SIDE

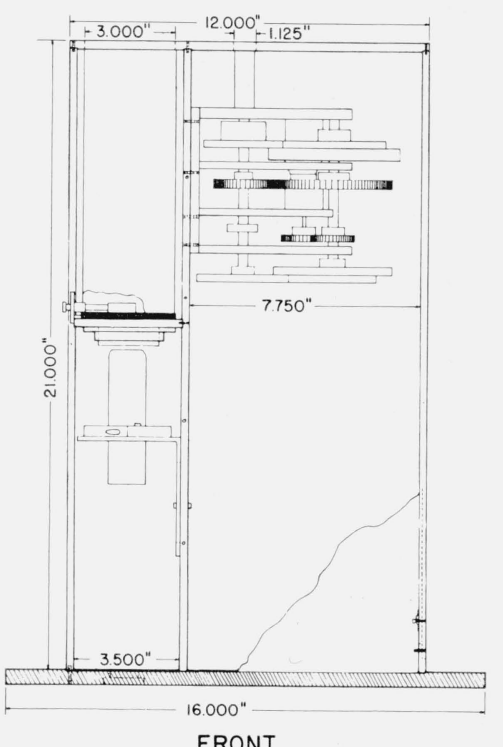

FRONT

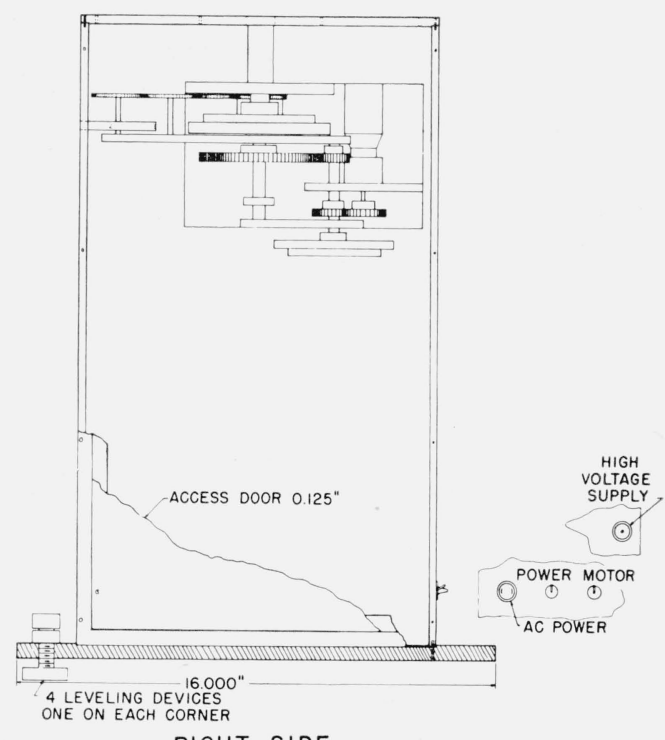

RIGHT SIDE

Figure 3.-Telescope drawing.

OBJECTIVE LENS
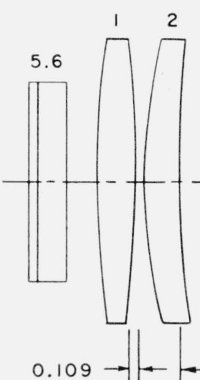

8.70

\begin{tabular}{|c|c|c|c|c|c|c|c|}
\hline \multirow{2}{*}{$\begin{array}{l}\text { Element } \\
\text { Number }\end{array}$} & \multirow{2}{*}{$\begin{array}{l}\text { Diam. } \\
\text { In. }\end{array}$} & \multicolumn{2}{|c|}{ Radi } & \multirow{2}{*}{$\begin{array}{c}\text { Center } \\
\text { Thickness }\end{array}$} & \multirow{2}{*}{$\begin{array}{c}\text { Index of Refr. } \\
\mathrm{N}_{\mathrm{D}}\end{array}$} & \multirow{2}{*}{$\begin{array}{l}\text { Eff. Focal L. } \\
\text { In. }\end{array}$} & \multirow[t]{2}{*}{ Material } \\
\hline & & Front & Rear & & & & \\
\hline 1 & 2.85 & 10.96 & -73.43 & 0.35 & 1.523 & 9.23 & Water white \\
\hline 2 & 2.85 & 5.77 & 14.43 & 0.41 & 1.523 & \multirow{2}{*}{0.73} & Plate glass \\
\hline 3 & 0.90 & 1.26 & -2.85 & 0.18 & 1.611 & & Dense barium \\
\hline 4 & 0.90 & 0.64 & 2.22 & 0.18 & 1.611 & & Crown, 3 \\
\hline 5 & $2 \times 2$ & \multicolumn{6}{|c|}{ Colored glass transmission filter } \\
\hline 6 & $2 \times 2$ & \multicolumn{6}{|c|}{ Interference filter } \\
\hline
\end{tabular}

A11 dimensions in inches

Figure 4. Telescope optics. 
airglow lines with only one detector. Voltage for the tube is supplied by a commercial plug-in high voltage supply, manufactured by the C. J. Applegate Company. The addition of a $20 \mathrm{~K}$ series resistance and a $10 \mathrm{mf} 2,000 \mathrm{v} \mathrm{d}$-c paper condenser in the output of the high volt power supply reduces the ripple at the output of the supply. The tube is operated at $1,000 \mathrm{v}$.

The amplifying system consists of an Electro Instruments model $\mathrm{A}-12$ d-c or A-14 d-c amplifier. This unit is an all-transistor amplifier that is chopper stabilized. Since, in general, the airglow intensities are independent of one another, four sensitivities will be needed for standard operation. The amplifier has a fixed gain and the individual gain adjustment for each of the four airglow intensities is accomplished by varying the size of resistor $R_{s}$. See figure 5 . The system is programed to change sensitivity each time a filter is moved into position in front of the telescope.

The dark current of the photomultiplier presents a problem as it does in any $d-c$ amplifier system. In order to eliminate its effect, a simple circuit is set up at the input of the amplifier which may be adjusted to feed the amplifier an equal and opposite current as shown in figure 5. Since the dark current is a strong function of the temperature, this adjustment is made readily accessible and can be adjusted periodically by the observer. Each of the four sensitivity adjustments available for each filter has its own dark current adjustment. This allows the operator to set the dark current adjustment for each sensitivity. The voltage supply for dark current balance, shown in figure 5 , uses a battery. Current drain is so extremely small that the shelf life of the battery is not shortened significantly. A galvanometric strip chart recorder is used to record the data. In order to match the characteristic impedance of the recorder and accomplish optimum time response, a driver stage was necessary as shown in figure 5. This stage is not necessary for servotype recorders.

\section{Mechanical Drive}

The movements of both turrets are controlled by purely mechanical means. An exploded view of the gear system is shown in figure 6 . The rotating turret "b" which holds the filters and turret " $a$ " which holds the standard light, the sky opening, and a blank position for a zero, are driven by two concentric shafts. Each has its own gear system, but both are driven by the same motor. The motor runs continuously and a periodic motion of the turrets is obtained by a Geneva drive system. Descriptions of this type of operation are available in the literature [Jones, 1930]. This type of motion combines high reliability with accurate positioning.

\section{Filter System}

The filters are mounted, as previously mentioned, in a disk which is periodically rotated into place. The particular line desired for study is selected by using an interference filter with a band pass of about $50 \mathrm{~A}$ at half transmission. Colored glass filters may be used to eliminate side bands. Any wavelengths within the sensitivity range of the detector may, of course, be observed by changing filters. The present instrument is equipped with filters centered at $5300,5577,5893$, and $6300 \mathrm{~A}$. The last three are centered on airglow lines. The first is in a region where there is relatively little airglow and is used to help subtract out the integrated starlight and light from other extraterrestrial sources.

\section{Calibration and Standard Light}

The problem of calibration is one of the more difficult in the airglow field [Roach, 1958]. There is a well-calibrated photometer at the NBS Fritz Peak airglow station. The absolute calibration is obtained by comparison with this instrument.

In order to maintain the calibration we are using, as previously mentioned, a standard light. This is a phosphorescent source using a radioactive decay product as the activator.

There are many phosphors on the market using radioactive decay products for activation. An inexpensive source may be made from a radium activated phosphor which is applied as paint. These sources do exhibit some decay resulting from damage of the phosphor by the heavy ionization due

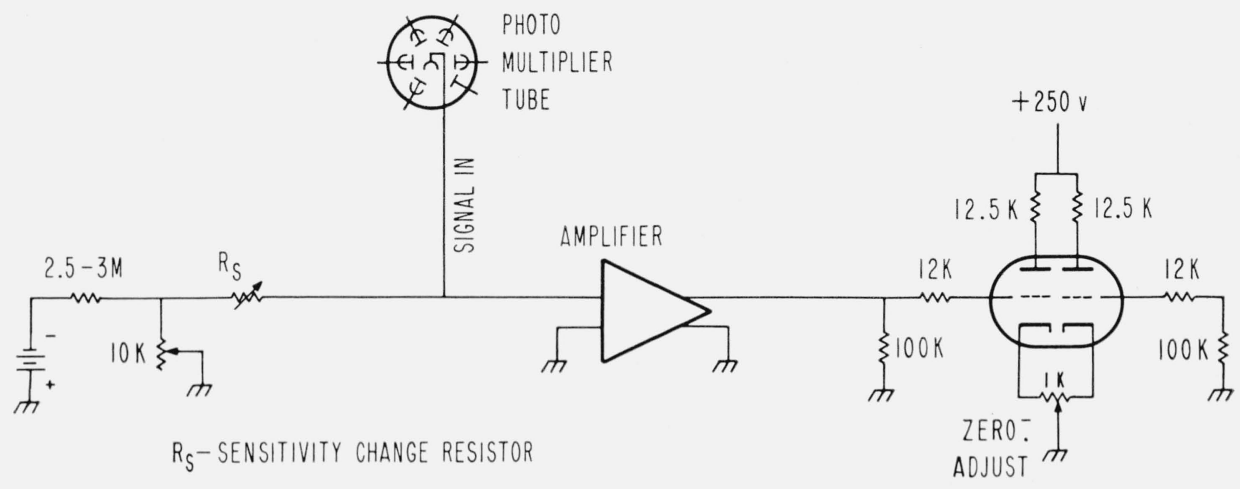

Figure 5. Simplified schematic of amplification system.

The signal output from the driver tube is taken directly from the plates of the tube. 


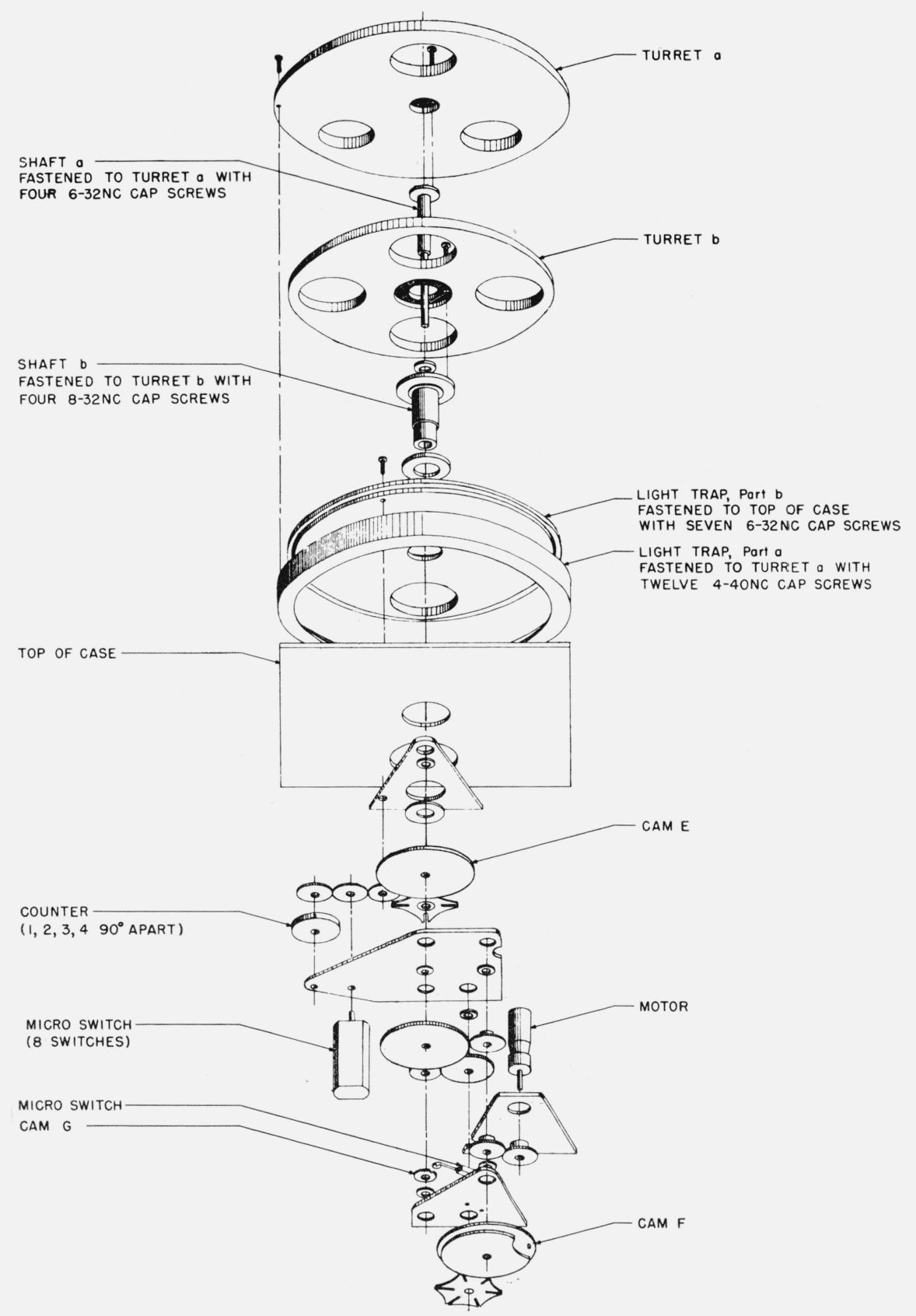

FIgure 6. Turret drive mechanism exploded assembly.

to the alpha particles from the radium. They are, however, quite good for considerable periods and easily obtained. Most phosphors available have peak response in the green and little emission in the red. This is also true of some tritium activated phosphors which have been used.

A phosphor which has been found to have good red emissions as well as the shorter wavelengths in the visible region is the U.S. Radium Corp. Isolite Standard Source. This contains a U.S. Radium Corp. red phosphor with carbon 14 as the activator. This phosphor is available with several types of radioactive activators.
The authors recognize the contributions of Ralph C. Darr of the NBS Instrument Shop for excellent workmanship, particularly in the design of the details of the Geneva motion.

\section{References}

[1] Jones, F. D., Editor, Ingenious Mechanisms for Designers and Inventors (The Industrial Press, 1930).

[2] Roach, F. E., The intercalibration of airglow photometers, unpublished (1958).

[3] St Amand, Pierre, A possible relation between the night airglow and the ionosphere, Thesis (California Institute of Technology, 1953).
(Paper 65C4-73) 